\title{
DAS MOBILIZAÇÕES ÀS REDES DE MOVIMENTOS SOCIAIS*
}

\author{
Ilse Scherer-Warren**
}

Resumo: A realidade dos movimentos sociais é bastante dinâmica e nem sempre as teorizações têm acompanhado esse dinamismo. Com a globalização e a informatização da sociedade, os movimentos sociais em muitos países, inclusive no Brasil e em outros países da América Latina, tenderam a se diversificar e se complexificar. Por isso, muitas das explicações paradigmáticas ou hegemônicas nos estudos da segunda metade do século XX necessitam de revisões ou atualizações ante a emergência de novos sujeitos sociais ou cenários políticos. Este estudo busca, inicialmente, uma compreensão acerca da nova configuração da sociedade civil organizada, explicitando os múltiplos tipos de ações coletivas do novo milênio. ${ }^{1}$ A partir desta compreensão, busca-se explorar a diversidade identitária dos sujeitos, a transversalidade nas demandas por direitos, as formas de ativismo e de empoderamento através de articulações em rede e, finalmente, a participação política das organizações em rede.

Palavras-chave: movimentos sociais, sociedade civil, redes, cidadania, empoderamento.

Versão preliminar deste trabalho foi apresentada no VII Corredor das Idéias do Cone Sul, Unisinos, em agosto de 2005 e no XXV Congresso da Associação LatinoAmericana de Sociologia (ALAS), Porto Alegre, em agosto de 2005.

** Professora do Departamento de Sociologia e Ciência Política da Universidade Federal de Santa Catarina e Coordenadora do Núcleo de Pesquisa em Movimentos Sociais da mesma universidade.

Artigo recebido em 5 mar. 2006 e aprovado em 13 maio 2006. 


\section{Novos formatos de organização da sociedade civil}

Parte-se aqui de uma noção genérica e contemporânea de sociedade civil. De fato, trata-se de um conceito clássico da sociologia política, mas, na atualidade, ele tende a ser utilizado num modelo de divisão tripartite da realidade: Estado, mercado e sociedade civil. ${ }^{2}$ Nesta perspectiva teórica, a sociedade civil, embora configure um campo composto por forças sociais heterogêneas, representando a multiplicidade e diversidade de segmentos sociais que compõem a sociedade, está preferencialmente relacionada à esfera da defesa da cidadania e suas respectivas formas de organização em torno de interesses públicos e valores, incluindo-se o de gratuidade/altruísmo, distinguindo-se assim dos dois primeiros setores acima que estão orientados, também preferencialmente, pelas racionalidades do poder, da regulação e da economia. É importante enfatizar, portanto, que a sociedade civil nunca será isenta de relações e conflitos de poder, de disputas por hegemonia e de representações sociais e políticas diversificadas e antagônicas. Às vezes, também, a sociedade civil é tratada como sinônimo de "terceiro setor", mas isso não é adequado e comporta certa ambigüidade. O termo "terceiro setor" tem sido empregado também para denominar as organizações formais sem fins lucrativos e não-governamentais, com interesse público. A sociedade civil inclui esse setor, mas também se refere à participação cidadã num sentido mais amplo. Pode-se, portanto, concluir que a sociedade civil é a representação de vários níveis de como os interesses e os valores da cidadania se organizam em cada sociedade para encaminhamento de suas ações em prol de políticas sociais e públicas, protestos sociais, manifestações simbólicas e pressões políticas. Esses níveis, presentes na sociedade brasileira, na atualidade, podem ser genericamente tipificados da seguinte maneira:

Num primeiro nível, encontramos o associativismo local, como as associações civis, os movimentos comunitários e sujeitos sociais envolvidos com causas sociais ou culturais do cotidiano, ou voltados a essas bases, como são algumas Organizações Não-Governamentais (ONGs), o terceiro setor. ${ }^{3}$ Essas forças associativistas são expressões locais e/ou comunitárias da sociedade civil organizada. Para citar 
apenas alguns exemplos dessas organizações localizadas: núcleos dos movimentos de sem-terra, sem-teto, piqueteiros, empreendimentos solidários, associações de bairro, etc. As organizações locais também vêm buscando se organizar nacionalmente e, na medida do possível, participar de redes transnacionais de movimentos (Movimento dos Trabalhadores Rurais Sem Terra, Movimento dos Catadores de Lixo, Movimento Indígena, Movimento Negro, etc.), ou através de articulações inter-organizacionais, característica central de outro nível a ser mencionado a seguir. Entretanto, no nível local existem também coletivos informais, sem nenhuma ou pouca institucionalidade, que lutam por modos de vida alternativos, por reconhecimento ou são produtores de novas formas de expressão simbólicas, como grupos de neo-anarquistas e outras tribos urbanas.

Num segundo nível, encontram-se as formas de articulação inter-organizacionais, dentre as quais se destacam os fóruns da sociedade civil, as associações nacionais de ONGs e as redes de redes, que buscam se relacionar entre si para o empoderamento da sociedade civil, representando organizações e movimentos do associativismo local. É através dessas formas de mediação que se dá a interlocução e as parcerias mais institucionalizadas entre a sociedade civil e o Estado. Essas articulações também se tornaram possíveis porque há meios técnicos que as viabilizam: a Internet e os e-mails são práticas cotidianas das redes do novo milênio. Os encontros presenciais podem ser mais circunstanciais e espaçados, quando a comunicação cotidiana está garantida pelos meios virtuais. Conseqüentemente, tem se observado um crescimento expressivo de redes de ONGs e associações, de fóruns e de redes de redes, conforme constatado em nossa pesquisa. ${ }^{4}$

Mas até agora destacamos formas organizacionais que possuem certa institucionalidade: algumas com registros legais e certificações, outras apenas com normas ou procedimentos internos à associação. Essas normas disciplinam o cotidiano de atuação do associativismo civil. Todavia, há formas de protestos sociais de maior abrangência, por um lado, e mais conjunturais, por outro, compondo 
o terceiro nível organizacional: são o que chamo de mobilização na esfera pública.

Nesse terceiro nível, observa-se que as mobilizações na esfera pública são fruto da articulação de atores dos movimentos sociais localizados, das ONGs, dos fóruns e redes de redes, mas buscam transcendê-los por meio de grandes manifestações na praça pública, incluindo a participação de simpatizantes, com a finalidade de produzir visibilidade através da mídia e efeitos simbólicos para os próprios manifestantes (no sentido político-pedagógico) e para a sociedade em geral, como uma forma de pressão política das mais expressivas no espaço público contemporâneo. Alguns exemplos ilustram essa forma de organização, incluindo vários setores de participantes: a Marcha Nacional pela Reforma Agrária, de Goiânia a Brasília (maio de 2005), foi organizada por articulações de base como a Comissão Pastoral da Terra (CPT), o Grito dos Excluídos e o próprio MST e por outras, transnacionais, como a Via Campesina. Também se realizaram articulações com universidades, comunidades, igrejas, através do encaminhamento de debates prévios à marcha. A Parada do Orgulho Gay tem aumentado expressivamente a cada ano, desde seu início em 1995 no Rio de Janeiro, fortalecendo-se através de redes nacionais, como a ABGLT, de grupos locais e simpatizantes. ${ }^{5}$ A Marcha da Reforma Urbana, em Brasília (outubro de 2005), resultou não só da articulação de organizações de base urbana (Sem Teto e outras), mas também de uma integração mais ampla com a Plataforma Brasileira de Ação Global contra a Pobreza. A Marcha Mundial das Mulheres tem sido integrada por organizações civis de todos os continentes. A Marcha vinculada à III Cúpula dos Povos, em Mar Del Plata (novembro de 2005), "foi convocada pela Aliança Social Continental, por estudantes, trabalhadores, artistas, líderes religiosos, representantes das populações indígenas e das mulheres, juristas, defensores dos direitos humanos, parte desse movimento plural, que, pela terceira vez, celebra o encontro, após os realizados em Santiago do Chile (1998) e Québec (2001)" (cf. Adital, 4 nov. 2005). A Marcha Zumbi +10 desmembrou-se em duas manifestações em Brasília (uma em 16 e outra em 22 de novembro 
de 2005), expressando a diversidade de posturas quanto à autonomia em relação ao Estado. Portanto, vale destacar, que essas organizações em rede abrem-se para a articulação da diversidade, mas com limites quanto à capacidade de absorção de posturas ideológicas ou políticas conflitivas, vindo a se cindir quando os conflitos se tornam não negociáveis, como no caso acima.

No nível da captação de recursos materiais de sustentação organizacional, registram-se os apoios financeiros, especialmente os das agências não-governamentais nacionais e internacionais e, freqüentemente, governamentais. Mas, há também contribuições individuais advindas do campo da solidariedade cidadã.

Finalmente, como resultado de todo esse processo articulatório vai se constituindo o que denominamos, enquanto conceito teórico, de rede de movimento social. Esta pressupõe a identificação de sujeitos coletivos em torno de valores, objetivos ou projetos em comum, os quais definem os atores ou situações sistêmicas antagônicas que devem ser combatidas e transformadas. ${ }^{6}$ Em outras palavras, o Movimento Social, em sentido mais amplo, se constitui em torno de uma identidade ou identificação, da definição de adversários ou opositores e de um projeto ou utopia, ${ }^{7}$ num contínuo processo em construção e resulta das múltiplas articulações acima mencionadas. A idéia de rede de movimento social é, portanto, um conceito de referência que busca apreender o porvir ou o rumo das ações de movimento, transcendendo as experiências empíricas, concretas, datadas, localizadas dos sujeitos/atores coletivos.

Na sociedade das redes (para usar uma terminologia de Manuel Castells), o associativismo localizado (ONGs comunitárias e associações locais) ou setorizado (ONGs feministas, ecologistas, étnicas, e outras) ou, ainda, os movimentos sociais de base locais (de moradores, sem teto, sem terra, etc.) percebem cada vez mais a necessidade de se articularem com outros grupos com a mesma identidade social ou política, a fim de ganhar visibilidade, produzir impacto na esfera pública e obter conquistas para a cidadania. Nesse processo articulatório, atribuem, portanto, legitimidade às esferas de 
mediação (fóruns e redes) entre os movimentos localizados e o Estado, por um lado, e buscam construir redes de movimento com relativa autonomia, por outro. Origina-se, a partir desse fato, uma tensão permanente no seio do movimento social entre participar com e através do Estado para a formulação e a implementação de políticas públicas ou em ser um agente de pressão autônoma da sociedade civil.

A Figura 1 ilustra o atual cenário da organização da sociedade civil, contemplando os níveis descritos.

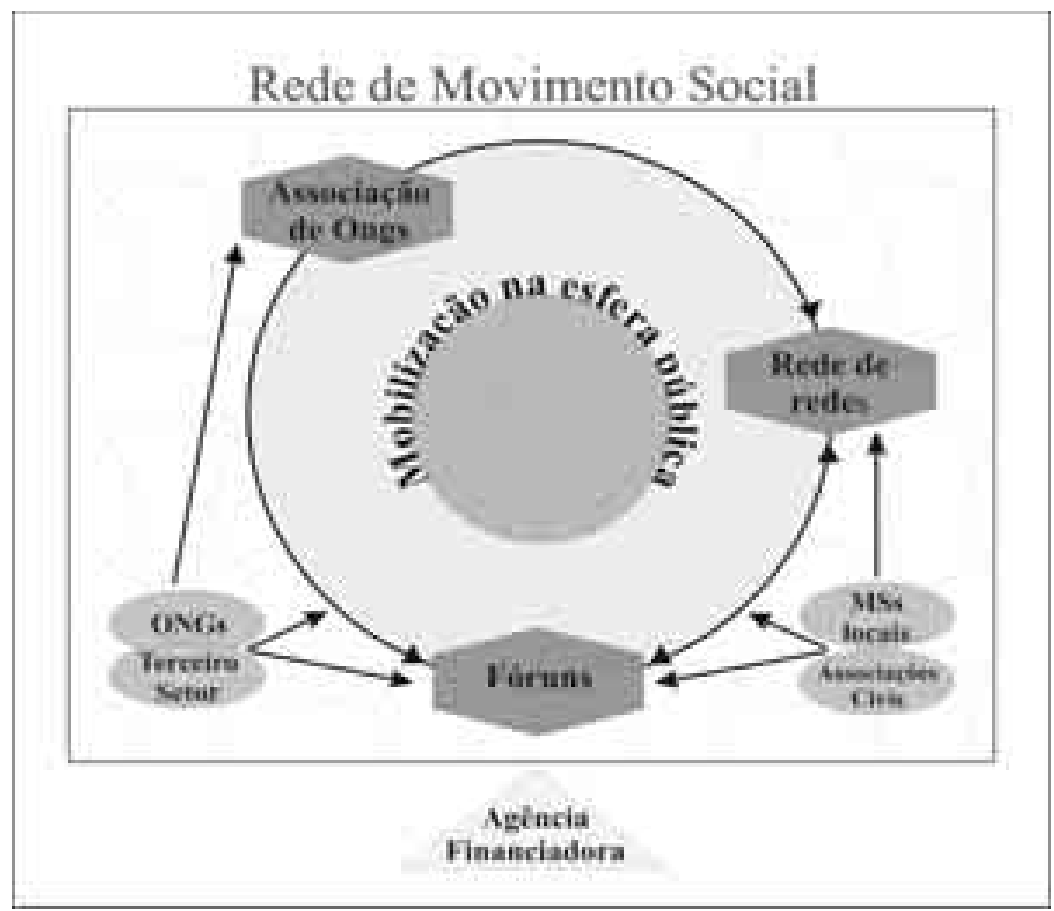

Figura 1 - Cenário atual da organização da sociedade civil

Fonte: Ilse Scherer-Warren, 2005.

Pode-se ilustrar uma rede de movimentos sociais através do Movimento Nacional Quilombola, ainda que se trate de um movimento emergente, na medida em que esse vem se constituindo numa expressão ativa do movimento negro brasileiro e pode ser considerado 
como uma rede, tendo em vista seus aspectos organizacionais e de ação movimentalista. ${ }^{8}$ Do ponto de vista organizacional, inclui várias redes de redes, desde a Coordenação Nacional de Articulação das Comunidades Negras Rurais Quilombolas (CONAQ), criada em 1996, até as organizações das comunidades locais de "mocambos", "quilombos", "comunidades negras rurais" e "terras de preto", que são várias expressões de uma mesma herança cultural e social, e ONGs e associações que se identificam com a causa. ${ }^{9}$ Do ponto de vista da ação movimentalista, apresenta as várias dimensões definidoras de um movimento social (identidade, adversário $e$ projeto): unem-se pela força de uma identidade étnica (negra) e de classe (camponeses pobres) - a identidade; para combater o legado colonialista, o racismo e a expropriação - o adversário; na luta pela manutenção de um território que vive sob constante ameaça de invasão, ou seja, pelo direito à terra comunitária herdada - o projeto. Nesse momento, unem-se também ao Movimento Nacional pela Reforma Agrária na luta pela terra, mas mantendo sua especificidade, isto é, pela legalização da posse das terras coletivas.

\section{A articulação em torno de novas identidades políticas e de valores}

Nas sociedades globalizadas, multiculturais e complexas, as identidades tendem a ser cada vez mais plurais e as lutas pela cidadania incluem, freqüentemente, múltiplas dimensões do self: de gênero, étnica, de classe, regional, mas também dimensões de afinidades ou de opções políticas e de valores: pela igualdade, pela liberdade, pela paz, pelo ecologicamente correto, pela sustentabilidade social e ambiental, pelo respeito à diversidade e às diferenças culturais, etc.

As redes, por serem multiformes, aproximam atores sociais diversificados - dos níveis locais aos mais globais, de diferentes tipos de organizações -, e possibilitam o diálogo da diversidade de interesses e valores. Ainda que esse diálogo não seja isento de conflitos, o encontro e o confronto das reivindicações e lutas referentes a diversos aspectos da cidadania vêm permitindo aos movimentos sociais 
passarem da defesa de um sujeito identitário único à defesa de um sujeito plural. Por exemplo, a Articulação das Mulheres Brasileiras $(\mathrm{AMB})$, rede tradicionalmente feminista, hoje

carrega um sub-título que diz Articulação de Mulheres Brasileiras uma articulação feminista e anti-racista. Isso se definiu afirmando o feminino e também afirmando o anti-racismo como uma questão central. Isso tudo é fruto das mulheres negras dentro da AMB... (Entrevista com Guacira, ex-coordenadora da AMB, 2005). ${ }^{10}$

A Marcha Mundial das Mulheres (MMM) é um caso emblemático de luta transversal de direitos para a América Latina e para a sociedade global. A MMM teve sua origem no movimento de mulheres e caracteriza-se por ser um projeto de mobilização social no qual participam ONGs feministas, mas também comitês e organismos mistos de mulheres e homens que se identificam com a causa do projeto. Essa causa parte do princípio da existência de uma discriminação de gênero, mas se associa à luta contra discriminações e exclusões sociais em outras dimensões, especialmente em relação à igualdade, solidariedade, liberdade, justiça e paz. Dessa forma, é central em sua plataforma política:

- o combate à pobreza (demanda por terra, trabalho, direitos sociais);

- o combate à injustiça (contra a violência em todas as esferas da vida social, que vai do tráfico de mulheres ao trabalho escravo até o cancelamento da dívida externa, como forma de exploração injusta).

Portanto, a MMM, como muitos movimentos sociais que se constituíram à luz dos movimentos alterglobalização, é uma rede interorganizacional, mas, no momento de suas mobilizações na praça pública se amplia consideravelmente com a presença de muitos(as) cidadãos(ãs) participantes, como ocorreu no lançamento da Carta Mundial das Mulheres para a Humanidade, em 8 de março de 2005, em São Paulo, onde foi estimada a presença de 30 mil mulheres de 16 Estados brasileiros e representantes de outros países (Mujeres de las Américas, 2005). A viagem da Carta pelas Américas permite não 
só uma ação integrada do movimento feminista latino-americano, mas também alianças com o conjunto dos movimentos sociais, em torno de uma pauta multidimensional que foi se construindo à medida que passava pelos vários países: por moradia, pela reforma agrária, por salário justo, saúde, direito ao aborto, pela paz, contra a violência, o racismo, a guerra, etc. - agenda essa que vai caracterizando uma face multi-identitária de um feminismo em movimento, latinoamericano e mundial. A Carta chegou a Burkina Faso, na África, no dia 17 de outubro de 2005, último porto dessa ampla rede mundial de solidariedade e de luta simbólica por "um outro mundo possível", lema do Fórum Social Mundial (FSM). ${ }^{11}$

Outras oportunidades políticas e reflexivas para as articulações em rede se encontram em fóruns transnacionais como o FSM e a Cúpula dos Povos da América. De fato, o FSM, ocorrido por quatro vezes em Porto Alegre, tem se constituído em um momento central de mobilização para as redes de movimentos na América Latina. O FSM, enquanto espaço de articulação da sociedade civil, tem servido de inspiração à criação de vários outros fóruns (por exemplo, o Fórum Brasileiro de Economia Solidária surgiu a partir do III FSM e o I Fórum Mundial da Saúde, ocorreu imediatamente antes do V FSM, realizado em Porto Alegre, em 2005); além de estimular o crescimento e o fortalecimento de outras redes, tais como a Via Campesina e a Marcha Mundial das Mulheres, já mencionadas.

\section{A transversalidade de direitos na luta pela cidadania}

O Fórum Social Mundial (FSM) bem como outros fóruns e redes transnacionais de organizações têm sido espaços privilegiados para a articulação das lutas por direitos humanos em suas várias dimensões sociais. Assim, através dessas articulações em rede de movimento observa-se o debate de temas transversais, relacionados a várias faces da exclusão social, e a demanda de novos direitos.

A transversalidade dos direitos tem uma referência organizada na Plataforma DhESCA (direitos humanos econômicos, sociais, 
culturais e ambientais), a qual defende a indivisibilidade dos direitos. Essa referência reflete o crescimento da presença de sujeitos e redes diversas no interior do Movimento Nacional de Direitos Humanos e no Fórum de Entidades Nacionais de Direitos Humanos (FENDH), no Brasil, onde se associaram às Comissões de Direitos Humanos, fundadoras do movimento, as pastorais sociais, ONGs, entidades indígenas, de negro(as), de mulheres, ambientalistas e outras, trazendo para o Movimento a necessidade da idéia de indivisibilidade dos direitos humanos.

O diagrama mostrado na Figura 2 representa a transversalidade das lutas sociais por direitos, através da atuação em redes.

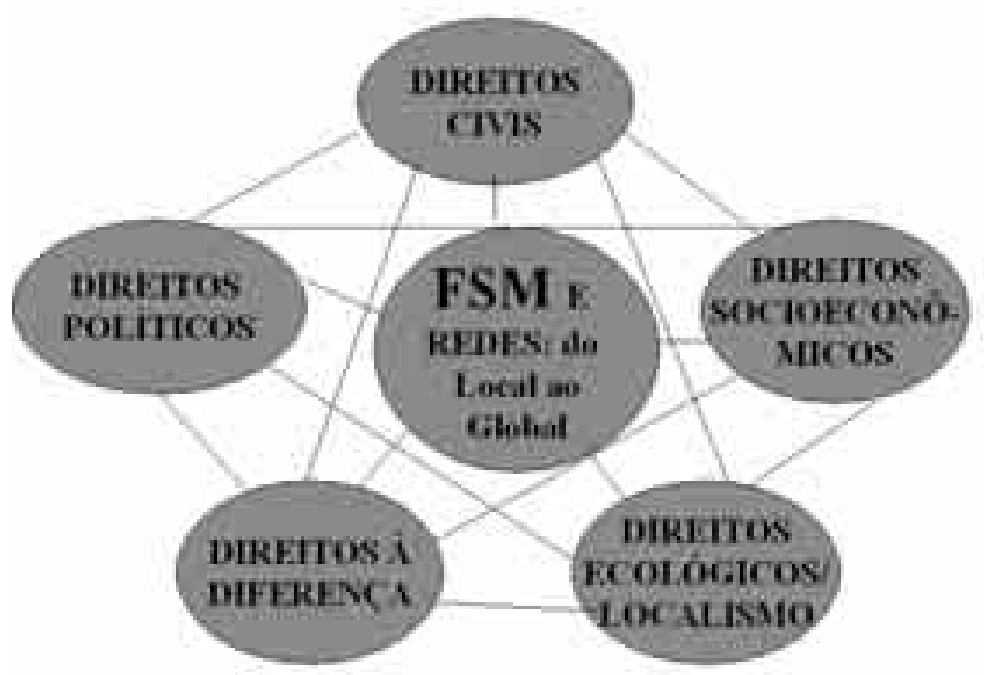

Figura 2 - Transversalidade das lutas sociais por direitos

Fonte: Ilse Scherer-Warren, 2005.

Essa transversalidade na demanda por direitos implica o alargamento da concepção de direitos humanos e a ampliação da base das mobilizações. Por exemplo, a Marcha Mundial das Mulheres (MMM) teve início numa manifestação pública feminista no Canadá, 
em 1999, cujo lema, inspirado em uma simbologia feminina - "pão e rosas" - expressava já a resistência contra a pobreza e a violência. Mantém até hoje esse primeiro mote, mas vem ampliando sua conotação, convocando o conjunto dos movimentos sociais para a luta por "um outro mundo", e por novos direitos humanos, onde sejam superados vários legados históricos do patriarcalismo e do capitalismo, conforme foi registrado na Carta Mundial das Mulheres para a Humanidade (2005, n. 6):

Esses sistemas se reforçam mutuamente. Eles se enraízam e se conjugam com o racismo, o sexismo, a misoginia, a xenofobia, a homofobia, o colonialismo, o imperialismo, o escravismo e o trabalho forçado. Constituem a base dos fundamentalismos e integrismos que impedem às mulheres e aos homens serem livres. Geram pobreza, exclusão, violam os direitos dos seres humanos, particularmente os das mulheres, e põem a humanidade e o planeta em perigo.

Essa luta pela transversalidade dos direitos humanos expressa na Carta Mundial das Mulheres para a Humanidade, possui cinco valores de referência: igualdade, liberdade, solidariedade, justiça e paz. Esses valores transformam-se em reivindicações coletivas da Marcha, das quais destacamos a síntese mostrada na Figura 3. Podem ser observados aí os direitos humanos clássicos e os direitos humanos de uma nova geração (das minorias e ambientais). Vale ressaltar que cada um desses direitos é perpassado pela conotação de uma luta contra a exclusão e a violência que contemple as dimensões de gênero, étnica, etária, regional, de eqüidade e de qualidade de vida. Portanto, é em torno dessa plataforma ampla que a MMM não só consegue se comunicar com o conjunto das tendências do feminismo, dos movimentos de mulheres de base local, mas também com os mais globais, com movimentos sociais de outras especificidades, com simpatizantes de suas causas, formando redes de redes de movimentos, identidades plurais, radicalizando a democracia a partir dos níveis locais, regionais, nacionais até os transnacionais na direção de uma cidadania planetária. 


\begin{tabular}{|l|l|}
\hline DIREITOS HUMANOS & EXEMPLOS DA PLATAFORMA \\
\hline CIVIS & $\begin{array}{l}\text { INTEGRIDADE FÍSICA E MORAL: } \\
\text { Contra tortura, tráfico sexual e de seres humanos, } \\
\text { mutilações, escravidão, a paz, etc. }\end{array}$ \\
\hline POLÍTICOS & $\begin{array}{l}\text { LIBERDADE COLETIVA E INDIVIDUAL: } \\
\text { Pensamento, opinião, participação na vida pública, } \\
\text { escolha, etc. }\end{array}$ \\
\hline ECONÔMICOS & $\begin{array}{l}\text { REDISTRIBUIÇÃO EQÜITATIVA DE RIQUEZAS: } \\
\text { Controle à pobreza, satisfação de necessidades especiais } \\
\text { e qualidade de vida e acesso a TICs... }\end{array}$ \\
\hline SOCIAIS & $\begin{array}{l}\text { PROTEÇÃO SOCIAL NECESSÁRIA: } \\
\text { Á alimentação, saúde, cuidado, educação, habitação, } \\
\text { segurança na velhice. Etc. }\end{array}$ \\
\hline $\begin{array}{l}\text { CULTURAIS E DIAS } \\
\text { MINORIAS }\end{array}$ & $\begin{array}{l}\text { LIBERDADE E RESPEITO À DIVERSIDADE: } \\
\text { À alimentação, saúde, cuidado, educação, habitação, } \\
\text { segurança na velhice, etc. }\end{array}$ \\
\hline $\begin{array}{l}\text { AMBIENTAIS E } \\
\text { MINORIAS }\end{array}$ & $\begin{array}{l}\text { PRESERVAÇÃO DO MEIO AMBIENTE: } \\
\text { Aos recursos naturais, patrimônio histórico, com controle } \\
\text { às manipulações genéticas. }\end{array}$ \\
\hline
\end{tabular}

Figura 3 - Síntese das reivindicações contidas na Carta Mundial das Mulheres para a Humanidade

Compilação: Ilse Scherer-Warren, 2005.

\section{$O$ ativismo nas redes de movimento}

Muitos têm afirmado que o ativismo e a militância vêm perdendo fôlego nas últimas décadas. A militância que se autodefinia como "revolucionária", certamente sim. Mas há um outro tipo de ativismo, que se alicerça nos valores da democracia, da solidariedade e da cooperação e que vem crescendo significativamente nos últimos anos. Por exemplo, o Movimento de Economia Solidária, que tem suas expressões empíricas nos empreendimentos populares solidários, no Fórum Brasileiro de Economia Solidária (FBES) e na Rede de Entidades Brasileiras de Economia Solidária (REBES), mostrou sua força organizativa no Fórum Social Mundial de 2005, pelo número de oficinas, experimentos e tendas organizados.

$\mathrm{O}$ ativismo de hoje tende a protagonizar um conjunto de ações orientadas aos mais excluídos, mais discriminados, mais carentes e 
mais dominados. A nova militância passa por essa nova forma de ser sujeito/ator. Portanto, a divisão clássica de ONGs "think tanks" (ou produtoras de conhecimento), ativistas (ou cidadãs) e prestadoras de serviço (ou de caridade) tende a dar lugar a organizações que mesclam, cada vez mais, essas três formas de atuação, ${ }^{12}$ tendo em vista seus compromissos com o pró-ativismo no campo da democracia.

Um exemplo emblemático do encontro do ativismo com um protagonismo mais pragmático pode ser encontrado nas ações do Fórum Brasil do Orçamento (FBO), especialmente em sua atuação pela construção democrática de uma Lei de Responsabilidade Social, orientada a partir dos seguintes princípios:

- Pagamento da dívida social brasileira;

- Publicização do Estado e monitoramento das políticas sociais;

- Empoderamento social e mudanças na gestão pública;

- Construção de um sistema de governança social.

Portanto, aí se conjugam reivindicações para a superação da exclusão social, para a transparência do poder público e para a participação ativa da sociedade civil organizada.

\section{O empoderamento nos movimentos sociais em rede}

Pode-se, enfim, indagar: Nos movimentos sob a forma de redes, as estruturas de poder se dissolvem? Pressupõe-se, freqüentemente, que, numa organização em rede há uma distribuição do poder, os centros de poder se democratizam, ou, como há muitos centros (nós/ elos), o poder se redistribui. Isso é parcialmente verdadeiro, porém, mesmo em uma rede há elos mais fortes (lideranças, mediadores, agentes estratégicos, organizações de referência, etc.), ${ }^{13}$ que detêm maior poder de influência, de direcionamento nas ações, do que outros elos de conexão da rede. Tais elos são, pois, circuitos relevantes 
para o empoderamento das redes de movimento. As redes, assim como qualquer relação social, estão sempre impregnadas pelo poder, pelo conflito, bem como pelas possibilidades de solidariedade, de reciprocidade e de compartilhamento. Portanto, o que interessa é saber como se dá o equilíbrio entre essas tendências antagônicas do social e como possibilitam ou não a autonomia dos sujeitos sociais, especialmente os mais excluídos e que, freqüentemente, são as denominadas "populações-alvo" desses mediadores.

Pergunta-se então: Como o trabalho de mediação das ONGs junto aos movimentos de base local pode ser direcionado ao empoderamento dos sujeitos sociais "socialmente mais excluídos", no sentido de não estimular as hierarquias de poder? Dentre outras, três orientações político-pedagógicas podem ser citadas como relevantes no trabalho de mediação social:

1) Atuar no sentido de resgatar a dignidade dos sujeitos socialmente excluídos, porque sem a desconstrução das discriminações introjetadas pelos dominados socialmente não há luta por direitos; atuar no sentido de resgatar positivamente suas raízes (culturais, simbólicas, estéticas), sem abrir mão de avaliações auto-críticas transformadoras, potencializando as iniciativas da base para enfrentar e resolver os problemas sociais (por exemplo, redes de arte e cidadania, desenvolvidas através de vários projetos sociais);

2) Promover novas formas de ação coletiva junto às populações excluídas (por exemplo, através de trocas solidárias, de trabalho cooperativo, de iniciativas artísticas e da mística), potencializando os mecanismos de reconhecimento social, de solidariedade, de cooperação, de confiança, de reciprocidade, enfim, construindo uma nova ética para o social.

3) Associar-se a outras experiências (articulação e trocas de experiências de vários coletivos em redes, formando redes de redes, e participando de mobilizações de base), ${ }^{14}$ 
empoderando-se, assim, na direção de uma rede de movimento social.

Enfim, as seguintes dimensões sociais merecem estar contempladas para um trabalho de empoderamento democrático e de inclusão social das bases: o combate à exclusão em suas múltiplas faces e a respectiva luta por direitos (civis, políticos, socioeconômicos, culturais e ambientais); o reconhecimento da diversidade dos sujeitos sociais e do respectivo pluralismo das idéias; a promoção da democracia nos mecanismos de participação no interior das organizações e nos comitês da esfera pública, criando novas formas de governança.

\section{Novas formas de governança na organização em rede}

Preparar os sujeitos para se tornarem atores de novas formas de governança requer a participação em diversos espaços: mobilizações de base local na esfera pública; empoderamento através dos fóruns e redes da sociedade civil; participação nos conselhos setoriais de parceria entre sociedade civil e Estado; e, nos últimos anos, a busca de uma representação ativa nas conferências nacionais e globais de iniciativa governamental em parcerias com a sociedade civil organizada.

No espaço das mobilizações de base local é onde se reafirmam e se consolidam:

- as identidades coletivas, reforçando o sentimento de pertencimento (o que é ser, se sentir e atuar como um semterra, um quilombola, um afro-brasileiro, um neo-zapatista, uma feminista, etc.);

- os simbolismos/místicas das lutas, criando-se a idéia de unidade na diversidade e força interior para prosseguir (através do culto a bandeiras dos movimentos, músicas, objetos culturais, ritos, etc.); 
- os projetos/utopias, que dão longevidade e significação ao movimento (projetos da reforma agrária, território comunal, ações afirmativas e igualitarismo e reconhecimento das diferenças de gênero, étnicas, etc.).

Portanto, é nesse espaço que o empoderamento político e simbólico das organizações de base local se constrói e se reconstrói de forma mais efetiva.

No espaço dos fóruns da sociedade civil é onde se vão construindo de forma mais sistemática, as propostas para a transformação social e formas de negociação com o Estado e o mercado. Para citar elementos das plataformas de alguns fóruns, que visam uma política de negociação com o Estado:

- Fórum em Defesa dos Direitos Indígenas (FDDI) - garantir direitos originários dos povos indígenas (especialmente a terra), conforme previsto na Constituição de 1988;

- Fórum de Entidades Nacionais de Direitos Humanos (FENDH) - participação no Plano Nacional de Direitos Humanos, com inclusão da Plataforma DhESCA;

- Fórum Brasil do Orçamento (FBO) - Campanha sobre Superávit Primário e pela Democratização da Lei de Responsabilidade Social;

- Fórum Nacional de Reforma Agrária (FNRA) - limite da propriedade da Terra (Carta da Terra, que contempla também um modelo de sociedade);

- Fórum do Lixo e Cidadania (FLC) - erradicar lixões, retirar crianças do lixão; criar coletas seletivas e geração de renda para os catadores.

- Articulação das Mulheres Brasileiras (AMB) integralidade e universalidade das políticas públicas de atendimento à mulher, contra a violência, contra o sexismo, contra o racismo, etc. 
Nesse espaço as organizações de base encontram um canal de representação (ainda que bastante informal) e de mediação política para as negociações com o Estado e o mercado.

Nas parcerias entre sociedade civil, Estado e mercado há múltiplas formas de atuação, mas em termos de participação para a elaboração de políticas públicas, merecem destaque os conselhos e conferências. Nos conselhos setoriais (popular e/ou paritário) é onde há, pelo menos teoricamente, um espaço institucional para o encaminhamento de propostas da sociedade civil para uma nova governança junto à esfera estatal. Alguns exemplos dessas parcerias podem ser citados:

- A Secretaria Especial de Políticas de Promoção da Igualdade Racial (SEPPIR) criou, em 2003, o CNPIR (Conselho Nacional de Promoção da Igualdade Racial), com 20 representantes da sociedade civil e 20 do governo, tendo caráter consultivo, para a interlocução entre sociedade civil e governo;

- Por ocasião da Mobilização Nacional Terra Livre, realizada pelo Movimento Indígena, na Esplanada dos Ministérios, em abril de 2005, durante a audiência com 30 lideranças indígenas, o ministro da Justiça, Marcio Thomaz Bastos, comprometeu-se com a criação de um Conselho Nacional de Política Indigenista - será um conselho para formulação de diretrizes da política para os povos indígenas, do qual participarão representantes dos índios, das entidades indigenistas e do governo;

- Os conselhos setoriais possibilitam também uma participação sistemática e institucional da sociedade civil organizada nas conferências nacionais e globais, como nas várias cúpulas e/ou conferências mundiais organizadas pela ONU e, no Brasil, nas Conferências Nacionais dos Direitos Humanos, das Mulheres, da Promoção da Igualdade Racial, dentre outras já realizadas, ou que estão sendo programadas, 
como as da Economia Solidária e da Juventude, organizadas a partir das Secretarias Especiais do Governo Federal;

- Resta lembrar os conselhos setoriais estaduais e municipais (crianças e adolescentes, saúde, segurança alimentar, educação, assistência social e outros), alguns com participação ativa das organizações da sociedade civil, outros ainda muito controlados pelo poder público. Frente a este desafio, Raichelis (2005), acrescenta que:

Estudos e pesquisas têm destacado a importância dos fóruns, plenárias, audiências públicas, mesas de concertação, redes e outras formas de articulação enquanto espaços políticos estratégicos para a ampliação da participação e democratização da informação, bem como mecanismos de ativação e dinamização dos próprios conselhos. No entanto, a dinâmica de funcionamento e o desenho organizacional desses novos espaços públicos precisam ser cuidadosamente pensados, pois condiciona, em larga medida, a capacidade de inclusão de novos atores coletivos, especialmente aqueles excluídos de outras arenas decisórias.

Enfim, a gestão das políticas públicas poderá ser mais ou menos cidadã, ou seja, influenciada pela sociedade civil. Isto dependerá das relações de força ou das possibilidades de convergência entre representantes das redes de movimentos, da esfera estatal e do mercado nos conselhos setoriais e nas conferências de promoção de direitos da cidadania; bem como das possibilidades e efetivo empoderamento e democratização no interior das próprias redes de movimento, na direção do desenvolvimento de sujeitos com relativa autonomia na construção de seus destinos pessoais e coletivos.

\section{Concluindo}

A sociedade civil organizada do novo milênio tende a ser uma sociedade de redes organizacionais, de redes inter-organizacionais e de redes de movimentos e de formação de parcerias entre as esferas públicas privadas e estatais, criando novos espaços de governança com o crescimento da participação cidadã. As redes de movimentos 
sociais possibilitam, nesse contexto, a transposição de fronteiras territoriais, articulando as ações locais às regionais, nacionais e transnacionais; temporais, lutando pela indivisibilidade de direitos humanos de diversas gerações históricas de suas respectivas plataformas; sociais em seu sentido amplo, compreendendo o pluralismo de concepções de mundo dentro de determinados limites éticos, o respeito às diferenças e a radicalização da democracia através do aprofundamento da autonomia relativa da sociedade civil organizada. ${ }^{15}$ Essa é a nova utopia do ativismo: mudanças com engajamento com as causas sociais dos excluídos e discriminados e com defesa da democracia na diversidade.

\section{Notas}

1 O trabalho tem por base alguns resultados de uma pesquisa em andamento sobre fóruns e redes nacionais de organizações da sociedade civil do Projeto "As múltiplas faces da exclusão social" (Projeto AMFES), do Núcleo de Pesquisa em Movimentos Sociais da UFSC, cuja pesquisa empírica foi realizada durante estágio enquanto pesquisadora visitante do CNPq, junto à Universidade de Brasília (UNB), no período de setembro de 2004 a agosto de 2005.

2 A sociologia contemporânea tem privilegiado essa perspectiva analítica, vide, dentre outros, o estudo já clássico de Cohen \& Arato, 1992.

3 Há distinções históricas sobre a origem dos dois termos e seu uso, nesse sentido vide a obra coletiva organizada por Haddad (2002).

4 Cf. o projeto "As múltiplas faces da exclusão social" (ver nota 1); destacase a multiplicidade de campos de atuação e de formas de articulação, no Brasil, e apenas para citar alguns exemplos:

Associações de ONGs

Associação Brasileira de ONGs (ABONG),

Associação Brasileira de Gays, Lésbicas e Transgênero (ABGLT), etc. Fóruns de entidades da sociedade civil

Articulação das Mulheres Brasileiras (AMB),

Fórum de Entidades Nacionais de Direitos Humanos (FENDH),

Fórum em Defesa dos Direitos Indígenas (FDDI),

Fórum do Lixo e Cidadania (FLC),

Fórum Brasileiro de Economia Solidária (FBES), 
Fórum Nacional de Mulheres Negras (FNMN),

Fórum Nacional de Prevenção e Erradicação do Trabalho Infantil (FórumPeti),

Fórum Brasil do Orçamento (FBO),

Fórum Nacional de Reforma Agrária (FNRA).

Redes de redes

Inter-redes Direitos e Política (Inter-redes),

Rede Cerrado,

Rede Brasileira de Sócioeconomia Solidária (RBSES),

Rede Mata Atlântica (RMA),

Rede de Informação do Terceiro Setor (RITS).

Na América Latina, para alguns exemplos

Consejo de Educación de Adultos de América Latina (CEAAL), Coalizão Rios Vivos, Via Campesina.

5 Em São Paulo, a primeira Parada Gay, em 1997, teve cerca de 2 mil pessoas e a nona, em 2005, cerca de 2,5 milhões. Cf. <http:// www.comunidadeglbt.com.br>.

6 Vide outros desdobramentos sobre a noção de redes de movimentos sociais em Scherer-Warren (1999, 2000, 2002 e 2005).

7 Cf. Touraine (1997), Melucci (1996), Castells (1996), entre outros.

8 No sentido atribuído por Doimo (1995).

9 Levantamento realizado sob a coordenação de Anjos (2005) mapeou a existência de 2.228 territórios quilombolas no Brasil.

10 Dados do Projeto AMFES (vide nota 1).

11 Neste dia chegou em Ouagadogou, Burkina Faso, a Carta Mundial das Mulheres para a Humanidade e a Colcha, que foi sendo costurada com os retalhos que expressam o mundo que querem as mulheres dos 53 países por onde a Carta passou.Cf. <http://www.marchamundialdas mulheres.org/news/2094>.

12 Vide a esse respeito, sobre as ONGs ambientalistas, a tese de Flávia Barros (2005).

13 O que ficou evidenciado em nosso trabalho de campo com organizações da sociedade civil (ver nota 1).

14 Sobre o assunto vide também Scherer-Warren (2002).

15 Sobre essas categorizações, vide Scherer-Warren (2005a). 
From social movements to the political participation of network organizations

\begin{abstract}
The reality of social movement is quite dynamic, and theorizations do not always follow this dynamism. With globalization and the information age, the social movements in several countries, including Brazil and Latin America, are more diversified and complex. Therefore, many paradigmatic or hegemonic explanations from the last century are in need of revision or updating vis-à-vis the emergence of new social subjects or political scenarios. This study begins by elucidating organized civil society's new forms, aiming to register the multiple types of collective action in the new millennium. From this comprehension the study seeks to explore the diversity of identity of the social subjects, the transverse nature of demands for citizen's rights, the forms of activism and the empowerment through networking and, finally, the political participation of network organizations.
\end{abstract}

Key-words: social movements, civil society, network, citizenship, empowerment.

\title{
Referências bibliográficas
}

ANJOS, Rafael Sanzio Araújo dos. Territórios das comunidades quilombolas no Brasil - segunda configuração espacial. Brasília: Mapas Editora \& Consultoria, 2005.

BARROS, Flávia. Banco Mundial e ONGs ambientalistas internacionais: ambiente, desenvolvimento, governança global, e participação da sociedade civil. Brasília, 2005. Tese (Doutorado em Sociologia) UNB.

CASTELLS, Manuel. The information age: economy, society and culture. London: Blackwell Publishers, 1996. $3 \mathrm{v}$.

COHEN, J.; ARATO, A. Civil society and political theory. Cambridge: MIT Press, 1992.

DOIMO, Ana Maria. A vez e a voz do popular. Rio de Janeiro: RelumeDumará, Anpocs, 1995.

HADDAD, Sérgio (org.). ONGs e universidades: desafios para a cooperação na América Latina. São Paulo: Abong; Peirópolis, 2002. 
MELUCCI, Alberto. Challenging codes: collective action in the information age. Cambridge: Cambridge University Press, 1996.

RAICHELIS, Raquel. Articulação entre os conselhos de políticas públicas: uma pauta a ser enfrentada pela sociedade civil. 2005. Paper.

SCHERER-WARREN, Ilse. Cidadania sem fronteiras: ações coletivas na era da globalização. São Paulo: Hucitec,1999.

. Movimentos em cena... as teorias por onde andam? In: SCHERERWARREN, Ilse, et al. Cidadania e multiculturalismo: a teoria social no Brasil contemporâneo. Lisboa: Socius, Florianópolis: Editora da UFSC, 2000. p. 23-51.

. Redes e sociedade civil global. In: HADDAD, S. (Org.). ONGs e universidades: desafios para a cooperação na América Latina. São Paulo: Abong; Peirópolis, 2002. p. 63-92.

Redes sociais: trajetórias e fronteiras. In: DIAS, Leila Christina; SILVEIRA, Rogério L. L. da (Orgs.). Redes, sociedade e território. Santa Cruz do Sul: EDUNISC, 2005.

Redes sociales y de movimientos en la sociedad de la información. Nueva Sociedad, Venezuela, n. 196, mar-abr. 2005.

TOURAINE, Alain. ¿Podremos vivir juntos? La discusión pendiente: el destino del hombre en la aldea global. Trad. Horácio Pons. Buenos Aires, Fondo de Cultura Económica, 1997. 